This item was submitted to Loughborough's Research Repository by the author.

Items in Figshare are protected by copyright, with all rights reserved, unless otherwise indicated.

\title{
The role of marketing in quality bus corridor promotion
}

PLEASE CITE THE PUBLISHED VERSION

PUBLISHER

(c) Thomas Telford

LICENCE

CC BY-NC-ND 4.0

REPOSITORY RECORD

Rye, Tom, and Marcus P. Enoch. 2019. “The Role of Marketing in Quality Bus Corridor Promotion”. figshare. https://hdl.handle.net/2134/3597. 
This item was submitted to Loughborough's Institutional Repository by the author and is made available under the following Creative Commons Licence conditions.

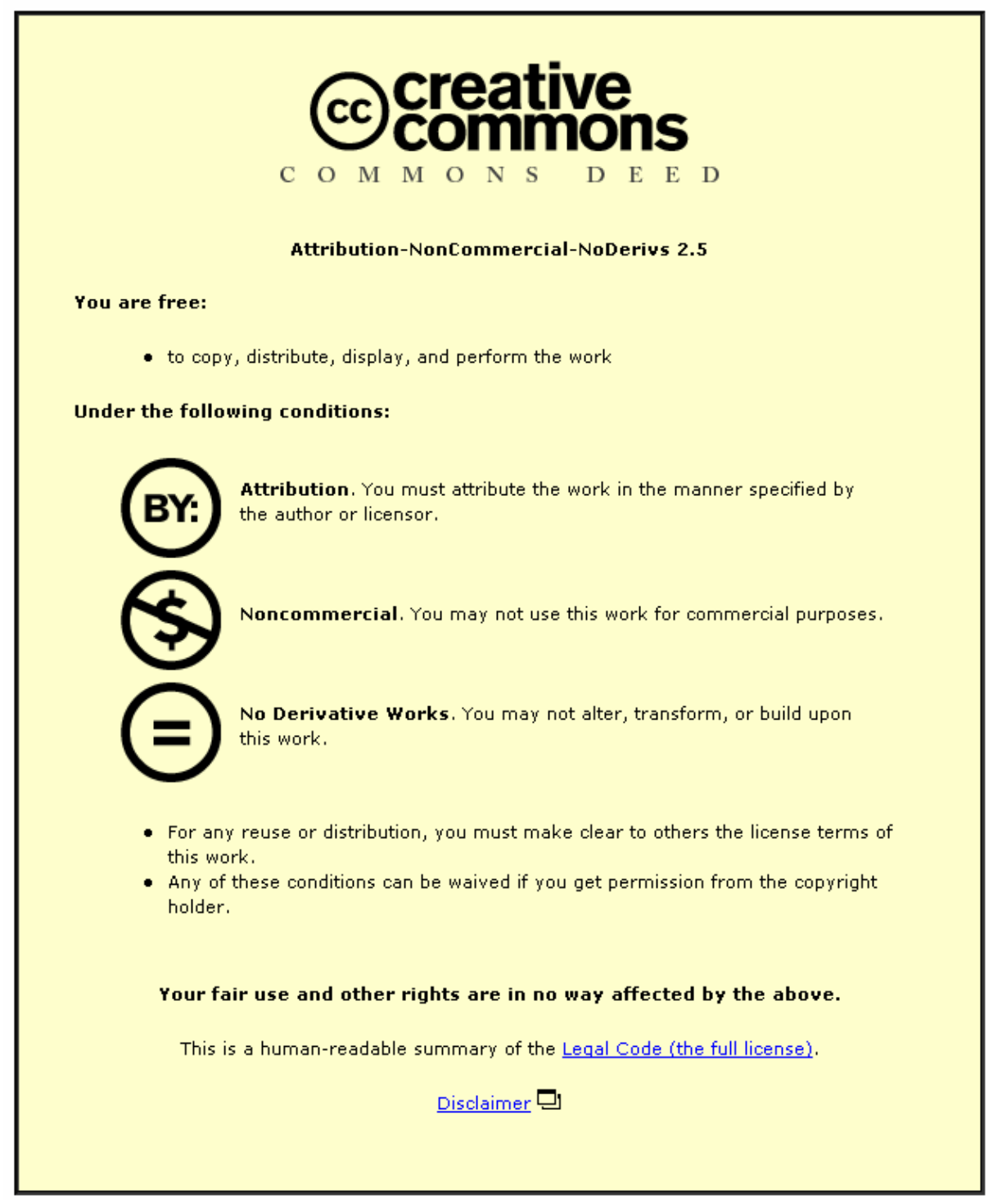

For the full text of this licence, please go to: http://creativecommons.org/licenses/by-nc-nd/2.5/ 


Proceedings of the Institution of
Civil Engineers
Municipal Engineer 157
March 2004 Issue MEI
Pages $61-66$
Paper 13555
Received $03 / 11 / 2003$
Accepted 09/02/2004
Keywords:
marketing \& public relations/
transport management/transport
planning

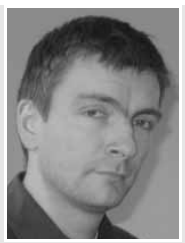

Tom Rye

Reader in Transport Studies,

School of the Built Environment, Transport Research Institute, Napier University, Edinburgh, UK

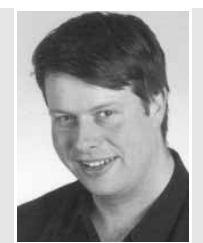

Marcus Enoch

Lecturer in Transport Studies,

Civil and Building Engineering. Loughborough University, UK

\section{The role of marketing in quality bus corridor promotion}

\section{T. Rye and M. Enoch}

Quality bus corridors (QBCs) are being implemented in towns and cities throughout the British Isles in order to improve the image of the bus and to boost patronage, with a view to meeting local and national transport policy objectives such as reduced reliance on the private car. QBC initiatives commonly consist of bus priority measures, improved vehicles, enhanced waiting environments, better information and, sometimes, enhanced service frequencies. The purpose of this paper is to examine the importance of the marketing of the QBC concept to the achievement of its objectives: are infrastructure and services sufficient, or will careful marketing increase awareness of the QBC and hence its overall effectiveness? To answer this question, the paper considers empirical experience of QBC implementation in one smaller and two larger urban areas in Britain-with its largely deregulated bus system-and the Republic of Ireland. Based on interview data from local authorities and operators, and on other unpublished information, comparisons are drawn between the QBC experience in Perth and Edinburgh in Scotland and Dublin in Ireland. The British examples are of interest because of their creation of an overall image for bus travel-through Greenways in Edinburgh, and Kick Start in Perth. Their Irish comparator has invested in vehicles and infrastructure, with less attention paid to the overall image of the QBCs. The paper will assess whether or not this is important.

\section{INTRODUCTION: OBJECTIVES AND STRUCTURE OF PAPER}

This paper addresses the importance of marketing in the overall effectiveness of quality bus corridors (QBCs). Local authorities and bus operators are aiming to increase bus ridership and win market share from their principal competitor, the private car. To do this, a range of measures are generally implemented to improve bus services: infrastructure such as bus lanes and better stops, improved frequencies and vehicles, and simplified fares and timetables. This paper explores the degree to which QBC implementation in two EU countries has included marketing of the concept in order to increase its impact; and it attempts to assess the importance of marketing, relative to other more infrastructure- and service-based improvements-insofar as these can be disentangled. (Note: Marketing is directly concerned with the selling of goods or services. In the public transport field, marketing activities are those directly concerned with the selling of public transport services or journeys. These might include improving the product by simplifying the route network, providing better information, conducting market research, or targeting specific user groups with promotions.)

To achieve the above aims, the paper first defines the range of improvements that can be implemented to grow the bus market. It then defines QBCs and marketing, before moving on to consider three empirical examples. Two of these are from Scotland-Stagecoach's Kick Start experiment in Perth, and Lothian Buses and its use of Greenways in Edinburgh. The third is from a different regulatory environment, but one with many institutional similarities to Britain: Dublin and its QBCs, in the Republic of Ireland. The paper compares the success of these initiatives and attempts to isolate the impact of marketing from other measures, thus drawing conclusions that are relevant to policy elsewhere in the British Isles.

\section{DEFINITIONS}

There are a range of measures that bus operators and local authorities can take to improve bus services. Previous work by the TAS Partnership ${ }^{1}$ has shown that on average these measures result in quite different levels of return on investment. It appears that the 'soft' measures related to the nature of the service and the way that it is marketed are, in the short to medium term at least, more cost-effective than 'harder' infrastructure investment in terms of return per pound expended (see Table 1). This analysis does not of course address the issue of whether, if the improvements are all implemented together, there is a cumulative impact beyond the individual cost-effectiveness figures shown in Table 1.

It has been argued elsewhere ${ }^{2}$ that the bus industry has, until recently at least, nonetheless displayed a tendency to address the less cost-effective measures. This is ascribed to a continuing public sector/local authority ethos in the industry, coupled with a greater interest among company managers in vehicles than in the service itself. Local authorities in Britain outside London are of course unable to influence the nature and branding of the services themselves, although many play a role in the provision of information.

\section{QBCS AND THEIR IMPACTS}

Quality bus corridors have been introduced in many parts of Britain over the past six to seven years. They have generally been 


\begin{tabular}{|lc|}
\hline Measure & $\begin{array}{c}\text { Approximate return per } \\
\text { pound spent: } \ell\end{array}$ \\
\hline Service simplification & 3.50 \\
Effective service promotion and & 3.10 \\
$\quad$ branding & 2.80 \\
High-quality signage and information & 2.20 \\
Bus stop improvements & 1.80 \\
New buses & 1.60 \\
Bus priority measures such as bus & 1.20 \\
lanes and signal priority & \\
Real-time passenger information/ & \\
automatic vehicle location equipment & \\
Table 1. Return per $€$ | of expenditure & \\
\hline
\end{tabular}

promoted by local authorities, working in collaboration with the bus operators on the corridors concerned. Consequently, much emphasis has been placed in QBC initiatives on the infrastructure aspects of the corridor. They have been used in order to provide priority for buses, and also to carry out traffic management works that have benefited all road users. These include junction improvements, new pedestrian crossings and junction entry treatments, and the rationalisation of on-street parking controls. The degree to which QBCs include bus priority varies widely, depending on constraints of local politics as well as the experience and attitudes of the traffic engineers and transport planners who design them. At one extreme, a QBC may include bus lanes wherever there is room to fit them in; at the other, an authority that is particularly afraid of adverse reaction from local traders and residents who fear the loss of on-street parking may simply upgrade bus stops, install bus priority at traffic signals, implement a bus lane where (and if) there are no other competing uses for the road space, and refer to this as a quality bus corridor.

In addition, some QBCs have seen the introduction of real-time bus information and better paper-based information, as well as (in some cases) improved bus service frequencies and newer buses. The emphasis which QBCs have placed on marketing the bus services that use them has been variable, due to the fact that this element is highly dependent on the attitude of the local management of the bus company (or companies) in the area.

In ridership terms, QBCs have achieved some impressive results. Three oft-quoted bus Quality Partnerships are found in the West Midlands. Known as 'Showcase' routes, Line 33 between Birmingham city centre, Kingstanding and Pheasey, Superline linking Coventry city centre and Foleshill, and Primeline connecting Walsall and Bloxwich, began operating in February 1997, June 1998 and August 1998 respectively. Patronage growth has been impressive: Line 33 up 28\%, Superline up 18\%, and Primeline up 5\% since their introduction.

\section{MARKETING AND ITS IMPACTS}

It has been shown that the most innovative bus companies in Britain-among them, Trent Barton and Brighton and Hove-have achieved year-on-year increases in patronage of $5-7 \%$ by adopting strategies based around a clear brand, innovative marketing, simple fares, networks and service frequencies, together with elements such as driver training and (in the case of Trent Barton), money-back guarantees. Simplification of whole networks in such cities as Glasgow, Leeds, Bradford, Bristol and Plymouth has reversed previous declines in patronage-by over $10 \%$ in Glasgow since 1998/99, for example. This has delivered improved services to the core market, although concentration of services on main routes and corridors has left some areas without any commercial service at all. The 'marketing approach'-one of creating a network worthy of being marketed, and then actively marketing it-has, however, shown itself able to maintain the viability of previously contracting networks, in the short term at least.

\section{EMPIRICAL EXPERIENCE AND OBSERVATIONS}

\section{I. Perth, Scotland}

This section is drawn from the Stagecoach publication Kickstart, ${ }^{3}$ which describes an experiment in bus marketing undertaken by the company in its operation in this medium-sized Scottish city.

Stagecoach identified a poor-performing, low-frequency bus route as a candidate for the Kick Start approach. The route had a profile of aged owner-occupiers with high car dependency. Perth and Kinross Council was about to introduce a bus priority scheme on the route, the first major use of such a scheme in the city. Further complementary local authority measures included new bus shelters and transponders to give buses priority at trafficlight-controlled junctions.

Stagecoach supported these steps by

(a) doubling the frequency of the bus service and introducing low-floor buses, although there was no business case in terms of historic profitability and the additional cost involved

(b) rezoning fares to make them simple and more understandable, resulting in a number of sizeable fare reductions

(c) devising and implementing a detailed marketing strategy

(d) distributing launch publicity and direct marketing to householders

(e) undertaking follow-up door-to-door interviews with potential customers, including a discussion of the Government's environmental targets, the new bus lanes and Stagecoach's new service

(f) offering free trips to prospective customers

( $g$ ) launching a programme of on-bus marketing, children's competitions, pensioners' lunches and other promotions.

In year 2 of the project, non-users were targeted through a tailored direct marketing campaign to offer the bus as a transport mode of choice. The results of the project were

(a) passenger growth of 56\% on the service for the first two years

(b) forecast of 63\% cumulative growth over a three-year period

(c) modal shift from private car to bus

(d) break-even point forecast for year 4, following a pattern of improved financial results: from a loss of $£ 120000$ in year 2 to a $£ 43000$ loss in year 3.

For more detailed figures see Reference 4. 
Revenue growth over the period has matched pricing as fares returned to original levels, with no elasticity observed. On the basis of primary research undertaken in Perth, new users in the city are less price-sensitive than in other areas of the UK.

Market research undertaken in Perth nine months into the project showed

(a) high user satisfaction levels of 89\%, significantly better than the Department of Transport, Local Government and the Regions (DTLR) Quality Indicators Report, ${ }^{5}$ which recorded average overall satisfaction levels of 79\% across the UK

(b) positive perception of the service by existing non-users, with $46 \%$ stating they would 'definitely' or 'very likely' use the Stagecoach service within the next few months.

Using this information, Stagecoach tailored a telephone-based direct marketing campaign specifically targeted at these nonusers to persuade them to travel by bus. This resulted in the conversion of $8 \%$ of those in the contact database to public transport and latterly feedback from these new customers has been very positive.

In this example then, it is clear that many elements that fall under the category of marketing have been very important in bringing about the more than 50\% increase in ridership. In particular, the route has been simplified, frequency increased, fares reduced and targeted marketing carried out. Bus priority was also installed but was quite modest in its extent compared with the other two examples examined in this paper; it consists of a few short lengths of bus lane together with improvements to bus stops, and some traffic management measures. One can infer, then, that the marketing elements (including service frequency increase) had a more significant impact on ridership than did the infrastructure, but it is difficult to disentangle the precise levels of influence of each. It should also be noted that the results of the Perth trial have not been evaluated independently, and that the company may be seeking to place the best possible 'spin' on its experience, in order to attract public-sector funding for further Kick Start type projects.

\subsection{Edinburgh}

Edinburgh, the capital of Scotland, is a city of 460000 people surrounded by other towns that bring the regional population to almost 900 000. It continues to enjoy economic success and consequently its transport system is under considerable stress. Due to its generally poor urban road infrastructure, limited citycentre parking, outlying social housing schemes and its highdensity core and inner suburbs, bus ridership in Edinburgh remains at about 200 trips per person per year, the highest in the UK outside London, making it a very strong bus market. Within the City of Edinburgh, fully $97 \%$ of bus services are commercial, although many of the longer-distance services into the city require subsidy.

The dominant bus operator in Edinburgh is Lothian Buses, with 550 vehicles running 19.5 million vehicle miles of service annually and carrying annual ridership of 91.5 million passengers. The direct descendant of the municipal tram company, it is one of the few UK bus operators that has not been privatised: it remains owned by four local authorities in the region, but it must operate as a public limited company without any direct control or subsidy from government. However, its owners are willing to accept a lower profit on turnover-about $12 \%$-than they would if it were owned by one of the major bus groups. It can be argued that this allows Lothian to run more services and to set lower fares than it would be able to if it were a stock market listed bus company required to return about 15\% on turnover. $^{6}$

Edinburgh's other major bus operator is First Edinburgh (formerly SMT), a unit of First Group, running approximately 260 vehicles in the area. Since deregulation, First/SMT and Lothian have had periodic bouts of on-road competition, such as in 2001/ 02 when First registered several services that had traditionally been run by Lothian. Generally, however, on-road competition has been limited to one or two routes, and the two operators have generally operated in geographically distinct areas: Lothian in the city and SMT/First to the outlying towns.

Greenways were introduced in 1997 as part of Edinburgh City Council's Moving Forward transportation strategy. The Greenways concept involved the phased introduction of $26 \mathrm{~km}$ of bus lanes on five routes in the city, representing a threefold increase on existing provision. Phase 1 comprised the implementation of measures on the A8 and A900 corridors, while Phase 2 added a further three routes which were opened in late 1998. They were an early example of the QBC concept, including the following measures.

(a) Bus lanes, surfaced in green, wherever road width permitted (i.e. not only in areas where congestion is a regular problem). This was to provide a clear message that this road space is reserved for buses and, indeed, anecdotally at least, many drivers appear to be under the impression that no driving is permitted in Greenways at any time of the day or night. In this sense, a strong image or brand was created for the Greenway, such that other non-Greenway bus priority (i.e. that not defined by a special Greenway Traffic Regulation Order) that has been installed since 1998 is also referred to as a Greenway by many people.

(b) In narrower sections of the road, red-surfaced advisory cycle lanes were installed.

(c) A new parking and loading regime, similar to that on London's Red Routes. This means, in effect, that on most parts of the Greenways, parking is not permitted between 0730 and 1830 Monday to Saturday, but loading is permitted in the interpeak. As noted above, this regime is defined by a special Traffic Regulation Order, and enforcement of parked as well as moving vehicles is the task of police traffic wardens rather than the council's parking attendants, who are confined to non-Greenway routes.

(d) Improvements to stops, shelters and timetable information at stops.

(e) Improved junction layouts, traffic calming to deter rat running round key junctions, and entry treatments of side-road junctions to improve conditions for pedestrians.

At the time of the introduction of the Greenways, there were no changes to bus services or additional marketing of the service by the main operator in Edinburgh, Lothian Buses.

A study of the effectiveness of Greenways by consultant Colin Buchanan and Partners for the Scottish Executive ${ }^{7}$ found that, in 
comparison with a route where 'conventional' bus priority was in operation, Greenways made a significant contribution to improved service reliability. This was due mainly to improved compliance by drivers and people parking on the Greenway compared with the conventional bus lanes, which was itself a result of higher levels of enforcement on the former routes. From an analysis of ticket machine data from one bus service that uses both the conventional bus priority and the Greenways, there was also evidence of a growth in patronage of $2 \%$ overall. This average masked increases in the peak hour of between $7 \%$ and $15 \%$ on different parts of the route. However, patronage growth was not confined merely to those parts of the route using the Greenway.

In 1998 a new management team was selected to change the perception of Lothian Buses as a very well-run but slightly staid company. This they did by investing in new buses (some 170 low-floor double-deckers since 1999, at a cost of $£ 21$ million, the latest with attractive tartan upholstery) and, crucially, rationalising their network. This strategy involved unifying low-frequency services running on virtually the same route to form one easily comprehended high-frequency route. Fares were also simplified (and reduced by about 15\% for longer trips), and a new off-peak day ticket was introduced. Since then, partly with the financial assistance of a new city-centre leisure complex, a revamped night bus network has been introduced, such that the most heavily-used services run on a 24-hour basis, at frequencies of up to four buses per hour.

New major trip generators-particularly a very large shopping centre/employment area to the west of the city, and also the administrative HQ of the new Scottish Government in the north of the city-were much better served. All bus stops now offer details of bus times, destinations served, and fares-sadly, innovative by UK standards. A new livery was adopted for Lothian's new buses, in an attempt to create a more modern brand, which is carried through to all marketing literature. Smartcards have been introduced for season-ticket holders, who can now purchase passes by direct debit. Bus-kilometres have increased by 10\% and, while key services are operated by new high-quality buses, Lothian has also invested in some 20 second-hand Leyland National buses to run on its secondary services.

After the implementation of these changes, patronage on Lothian Buses began to rise, reversing the trend of continual decline that had been apparent since the 1950s. Total bus passenger boardings in the former Lothian Regional Council area (which is dominated by Lothian buses passengers in numerical terms) increased from 98 million in 1998/99 to 114 million in 2001/02. ${ }^{89}$ This rise of almost $15 \%$ can be ascribed to the following four main factors-although their individual importance is almost impossible to disentangle

(a) the changes in Lothian Buses' operation, fares and marketing over the past three years, as described above

(b) the city council's introduction of bus priority on Greenways and, since then, on other routes

(c) the city council's long-standing restraint-based parking policy in the central area of the city (although this did not become any more restraint-based in the period 1998-2002)

(d) a continuing increase in employment in Edinburgh, including in the city centre, and a decline in surrounding areas, leading to longer-distance commuting, some of it by bus.

\subsection{Dublin}

During the 1990s, with economic growth of around 10\% per year, Dublin was facing worsening levels of traffic congestion. This led in 1994 to the publication of the Dublin Transportation Initiative ${ }^{10}$-the first integrated study of transport in the city-which in turn resulted in a virtual halt to urban road building (although the C-ring, the M50 motorway around the city was given the go-ahead), three LRT lines (now two) and a number of so-called QBCs-eleven radial, and one orbital.

The goal of the QBC is “to provide a clearly defined, high performance bus transportation system segregated from other traffic'. ${ }^{11}$ In practical terms, the aim is to deliver bus journey speeds on the corridor of at least $20 \mathrm{~km} / \mathrm{h}$, with a minimum increase in bus journey speeds of 25\% on all corridors; in addition, buses must be segregated from other traffic along the complete length of the corridor, except where the road width is too narrow to provide a bus lane. Further, it is aimed to provide high-quality waiting areas with real-time passenger information throughout, while buses will have an average age of only five years, be accessible to mobility-impaired people, be distinct in appearance from other buses and be air-conditioned. Finally, average waiting times for passengers were set at 3 min during the peak and $4 \mathrm{~min}$ in the off-peak, with an average excess wait of 2 min allowed. According to a representative of Dublin Bus, peak-hour bus frequencies are as high as one bus every 35-40 s on the Malahide Road corridor, and average 90 s across the QBCs as a whole-but off-peak frequencies are closer to one bus every $10 \mathrm{~min}$. Being able to deliver a very highly peaked service such as this requires subsidy: Dublin Bus' Annual Report $2002^{12}$ shows that approximately $25 \%$ of its total income was made up of government grant (excluding one-off grants to buy new buses). The comparable figure for Lothian Buses in Edinburgh is approximately $12 \%$, including tendered service support and a bus service operating grant (BSOG) (formerly fuel duty rebate).

As of late 2002, $98 \mathrm{~km}$ of bus lanes forming nine QBCs are in place, and three remain to be developed, namely Orbital, South Clondalkin and Ballymun. The results are impressive. In total, bus use in the morning peak (0700 - 0915 Monday to Friday) inbound services have increased by 38\%, from 138500 to 191500 passengers since 1997, while on the Stillorgan QBC, patronage rose by $232 \%$. Further, cordon counts on the 'canal ring' of traffic entering the city show that the modal share of the bus increased from 36.8\% in 1997 to $40.5 \%$ in 2001 . These counts also showed that some $60-65 \%$ of new bus users had switched from the car.

Altogether, QBC implementation costs are around $€ 57$ million for $98 \mathrm{~km}$, or $€ 575000$ per $\mathrm{km}$. While installing the lanes was relatively cheap, the cost of providing traffic signal improvements, additional cycle lanes and a whole raft of 'village improvements'-necessary for gaining local approval of the process-was significantly higher. The QBCs were mainly funded through European Regional Development Funding and Traffic Management Grants from the Dublin Transportation Office, the regional transport and planning authority (Dublin Bus, personal communication, 2002; and Reference 11). 
The QBC concept in Dublin has brought to passengers the following

(a) much reduced journey time and much increased reliability, thanks to increased numbers of buses as well as route-length bus priority

(b) newer buses

(c) improved stops.

However, in comparison with the marketing approach to bus services outlined in this second section of the paper, bus services in Dublin have not benefited from

(a) consistent route branding (route branding using the 'Cityswift' brand was attempted, but was unable to be maintained)

(b) more consistent provision of high-quality information

(c) money-back guarantees

(d) route and fare simplification

(e) any novel marketing techniques, such as targeting particular groups of potential passengers, although leaflet drops to the local area were carried out before the launch of each QBC scheme.

Nonetheless, the increases in passenger numbers on the corridors concerned cited by Dublin Bus and Dublin Transportation Office for QBCs in Dublin appear to surpass any large-scale experience of investment in bus infrastructure and services in Britain outside London-although the Kick Start experiment in Perth has achieved more impressive results in terms of percentage growth rates, albeit only on one route. This is in spite of a lack of any significant marketing elements in Dublin's bus strategy. This may suggest that the key to significant increases in bus patronage, and to modal shift from car to bus, is to install route-length bus priority and to increase frequencies to one bus every 2 min or better. However, there are also specific factors that may help to explain the particularly spectacular increase in ridership on Dublin's QBCs (if not on the Dublin network overall). These are all related to the city's high rate of economic growth, which may have brought about

(a) a dramatic increase in the number of cars on the road with a corresponding almost overnight deterioration in traffic congestion and pressure on parking, which may act as more of a stimulus to modal shift than do incremental changes

(b) a high degree of churn in the labour market-people change job frequently and thus reconsider their choice of mode for the journey to work more frequently than in more stable labour markets

(c) an influx of new labour, and hence demand for the bus.

A final point is that while no significant deliberate effort has been made to introduce 'marketing' as part of the Dublin QBCs, and the infrastructure and service aspects are in themselves so strong as to make the impacts of any marketing difficult to discern, the QBCs did benefit significantly from free-if not entirely positivepublicity generated by the controversy that surrounded their introduction.

\begin{tabular}{|c|c|c|c|}
\hline Measure & Perth & Edinburgh & Dublin \\
\hline Bus lanes & $\begin{array}{l}\text { Limited, very short lengths close } \\
\text { to junctions; special vehicle } \\
\text { detection (SVD) at signals }\end{array}$ & $\begin{array}{l}\text { Full-length lanes wherever physically } \\
\text { possible; special vehicle detection } \\
\text { (SVD) at signals }\end{array}$ & $\begin{array}{l}\text { Full-length lanes wherever } \\
\text { physically possible }\end{array}$ \\
\hline Bus stops & Boarders and shelters & Boarders and shelters & Improved shelters \\
\hline Vehicles & $\begin{array}{l}\text { More modern vehicles, low } \\
\text { floor }\end{array}$ & $\begin{array}{l}\text { Investment in new vehicles but not } \\
\text { coincident in time with } \\
\text { introduction of bus priority }\end{array}$ & New double-deckers \\
\hline Frequency & Doubled to $4 \mathrm{bph}$ & $\begin{array}{l}\text { Frequencies not increased but } \\
\text { services simplified }\end{array}$ & Increased to every $90 \mathrm{~s}$ in peak \\
\hline Routes & Concerns only one route & $\begin{array}{l}\text { Simplification and some } \\
\text { rationalisation to main corridors }\end{array}$ & $\begin{array}{l}\text { Services concentrated to use } \\
\text { corridors but still relatively } \\
\text { complex }\end{array}$ \\
\hline Ticketing & Simplified fares & $\begin{array}{l}\text { Simplified fares structure, exact fare } \\
\text { only, daily and longer-period } \\
\text { tickets available }\end{array}$ & $\begin{array}{l}\text { Zone fares, poorly explained. Exact } \\
\text { fare only. Passes available }\end{array}$ \\
\hline Branding & Yes & Attempted but not maintained & Attempted but not maintained \\
\hline Information & $\begin{array}{l}\text { Direct marketing to households } \\
\text { along route }\end{array}$ & $\begin{array}{l}\text { Comprehensive timing, fares and } \\
\text { route information from each stop }\end{array}$ & Poor at stops \\
\hline Leaflets & $\begin{array}{l}\text { Yes, considerable targeted } \\
\text { marketing }\end{array}$ & $\begin{array}{l}\text { Local area at launch of bus priority, } \\
\text { plus wider distribution-ongoing }\end{array}$ & Local area only at launch \\
\hline Economic activity & Buoyant & Rapid growth & Rapid growth \\
\hline Congestion & Low levels of congestion & $\begin{array}{l}\text { Deterioration in suburbs; static in } \\
\text { city centre }\end{array}$ & Deterioration \\
\hline Parking & $\begin{array}{l}\text { Very low parking prices in city } \\
\text { centre (c. } 25 \text { p per hour) }\end{array}$ & $\begin{array}{l}\text { Small real-terms increases in } \\
\text { on-street parking charges } \\
\text { 1998-2004 }\end{array}$ & Harder to find and more expensive \\
\hline $\begin{array}{l}\text { Impact on } \\
\text { ridership }\end{array}$ & $56 \%$ increase in first two years & $\begin{array}{c}\text { I } 5 \% \text { rise in passengers network- } \\
\text { wide, } 1998 / 99 \text { to } 2001 / 02\end{array}$ & $\begin{array}{l}9 \% \text { rise in passengers network- } \\
\text { wide, 1998/99 to 2001/02; 38\% } \\
\text { increase on QBCs in am peak, } \\
\text { 1997-2002. Modal shift from car }\end{array}$ \\
\hline
\end{tabular}




\section{SUMMARY AND CONCLUSIONS}

By way of conclusion, Table 2 compares the measures introduced in the three case study cities. The empirical examples presented in this paper cannot easily disentangle the respective influences of the marketing approach, compared with the introduction of QBC infrastructure alone. The Scottish and other British examples appear to highlight the importance of the former, while the case of QBCs Dublin to an extent demonstrates the opposite-at the route level, at least. However, the network-wide effects are somewhat different. Dublin Bus enjoyed a total increase in patronage of 9\% between 1998 and 2002, ${ }^{13}$ compared with the $15 \%$ seen in the former Lothian Region (which is dominated by Lothian Buses). Even the Trent Barton and Brighton and Hove networks, which have not benefited from extensive bus priority, have demonstrated higher rates of passenger growth than has Dublin Bus. The 'marketing approach' appears, from these examples, therefore, to be more effective than the infrastructure approach, at the network level. From a policy point of view, the final conclusion is perhaps the most self-evident: that, for maximum effect, both should be done together.

\section{REFERENCES}

1. TAS PARTNERSHIP. Modal shift: essential components of success. Proceedings of a Local Transport Today/TAS Partnership Conference: The Role of Buses in the New Transport Policy Environment, London, 23 June 1998.

2. Enoch M. and Potter S. Marketing and the British bus industry. Municipal Engineer, 2002, 151, No. 1, 49-56.
3. Stagecoach Plc. Kickstart. Stagecoach, Perth. Downloaded on 28/10/03 from http://www.stagecoachgroup.com/sgc/ investorinfo/reports/kickstart/kickstart.pdf

4. Souter B., Nash P., Rosscraig E. and Stewart S. Kick Start-better value, better bus services. Proceedings of the Institution of Civil Engineering-Municipal Engineer, 2004, 157, No. 1, 7-11.

5. Department of Transport, Local Government and the Regions. Bus Quality Indicators. Report, Quarter 4 Jan-Mar 2000/2001, DTLR, London, 2003.

6. White P. Public Transport-Its Planning, Operations and Management. Ashgate, London, 2001.

7. Colin Buchanan and Partners. A Comparative Evaluation of Greenways and Conventional Bus Lanes. Scottish Executive Central Research Unit, Edinburgh, 2000.

8. Scottish Executive. Bus and Coach Statistics: 2001-02. Statistical Bulletin Transport Series Trn/2003/2, Edinburgh, 2002.

9. Lothian Buses plc. Annual Report and Accounts 2001. Lothian Buses, Edinburgh, 2002.

10. Department of the Environment. Dublin Transport Initiative. Report, Department of the Environment (Irish Republic), Dublin, 1995.

11. Dublin Transportation OfFice. Quality Bus Corridors. Internal paper, Dublin Transportation Office, Dublin, 2002.

12. Dublin Bus. Annual Report and Financial Statements 2002. Dublin Bus, Dublin, 2003.

13. CIE Group. Annual Report 2002. CIE Group, Dublin, 2003.

Please email, fax or post your discussion contributions to the secretary by I September 2004: email: kathleen.hollow@ice.org.uk; fax: + 44 (0)20 7799 1325; or post to Kathleen Hollow, Journals Department, Institution of Civil Engineers, I-7 Great George Street, London SWIP 3AA. 